\title{
PUBLIC PERCEPTION AND AWARENESS ON CLIMATE CHANGES AND THE IMPORTANCE OF RENEWABLE ENERGY SOURCES
}

\author{
UDC: $502.17: 551.583$ \\ 620.91 \\ Original scientific paper \\ https://doi.org/10.18485/aeletters.2020.5.2.5
}

\section{Bogdana Vujic ${ }^{1}$, Jasmina Pekez ${ }^{1}$, Visnja Mihajlovic ${ }^{1}$, Ljiljana Radovanovic ${ }^{1 *}$, Una Marceta ${ }^{1}$, Ivan Palinkas $^{1}$}

${ }^{1}$ University of Novi Sad, Technical Faculty "Mihajlo Pupin" in Zrenjanin, Republic of Serbia

\begin{abstract}
:
Serbia, as a developing country and EU accession country, faces many challenges. One of the key areas identified as the most complicated problem in the negotiation process is the issues of environmental protection and improvement, including the energy sector. Since population in Serbia is concerned because of poor living standards, high unemployment rate, and other social issues it could be questioned what is their concern and awareness about climate change since it is a realistic and visible phenomenon that is hard for someone to ignore and neglect. This paper presents some of the results of a survey conducted among adults in rural and urban parts of the Autonomous Province of Vojvodina on their perception, awareness, and knowledge about climate change issues. The research/survey also examined the specific actions that respondents would take as a personal contribution to mitigating the effects of climate problems. The results indicate that respondents have a high awareness of climate change, but the knowledge on climate change is relatively low even though the respondents graduated from faculty (about 52\%).
\end{abstract}

ARTICLE HISTORY Received: 13.05.2020. Accepted: 22.06.2020. Available: 30.06.2020.

\section{KEYWORDS}

Climate change, public perception, renewable energy sources

\section{INTRODUCTION}

The critical issue in global/world problems is undoubtedly the problem of climate change (CC), which is receiving increasing attention from the world political scene.

The main global impacts of climate change are environmental changes such as increasing global average temperatures, melting polar ice caps and rising sea levels [1-3], but there are downstream effects too, which refers to impact on health and healthcare [4].

If we look at local climate change, we can say that the negative effects have been noticeable in Serbia in recent decades. There have been episodes of heavy rainfall, extremely high temperatures and prolonged periods of warm weather and droughts, as well as very low temperatures [5].
However, while the effects of climate change are increasing, and there is a demonstration of a will for climate change action, but not a strong action for the implementation of measures to prevent CC consequences. On the other hand, the question of what the actual level of public awareness and personal perception and view on the $\mathrm{CC}$ issue isarises.

In Serbia, the general issue of environmental protection, including $\mathrm{CC}$, should be given the highest priority in political agenda [6], given the fact that the environmental issues (Chapter 27) and energy issues (Chapter 15) in EU accession negotiations are ranked as areas that need to be invested to reach EU standards. On the other hand, although policymaking for the environmental protection and promotion of the environmental issues are tasks of public authorities and policymakers, national awareness, as well as the 
the awareness and perception of individuals can play a key role in the realization and implementation of action plans [7].

Public awareness and perception on CC issue have been in the researcher's focus for long time. In recent studies researcher investigated public awareness and through, demographic, geographic, socio-economic, educational and politics aspects [8-11].

The public's perception of climate change is different around the world. In recent years global concerns about climate change have risen in many parts of the world, but in the other handsome studies have shown growing skepticism in some developed countries [12]. Globally, the public in North America, Japan and Europe has the highest awareness of climate change, while in developing countries in Africa and Asia, most of the population (eg more than $65 \%$ in Egypt and Bangladesh) have never heard of climate change [13]. Most people in China are aware of climate change and public sensibility to climate change is high. [14]. Public perceptions at the national level are influenced by different demographic, cultural, geographical and political structures [15].

In developed countries such as the UK, terrorism, crime and vandalism are seen by the public as a much more important problem for their local environment as opposed to global warming (with a 2: 1 ratio) [16]. Russia, on the other hand, is conducting profoundly serious research into climate change, but the population does not have a clear conception of what is happening [17]. In surveys conducted in Canada and the US, $61 \%$ of US residents and $57 \%$ of Canadian residents consider CC as a serious problem [18]. In the United States, about $40 \%$ of the public is concerned that climate change will affect them personally, and most believe that negative impacts will be a global problem [19]. In developing countries, on the other hand, respondents who have heard about CC are more concerned about the effects of CC and the impact on their families than it is with the population in developed countries [13].

However there is also declining in public attention and concern about CC in several past years [20-21] that has been influenced by different complex factor such as intesive media coverage or some failure political events [22].

Research and data on individual perceptions and knowledge of adults in Republic of Serbia is rare, so the aim of this paper is to examine the population in urban and rural parts of AP Vojvodina about their perception, knowledge and behavior regarding $\mathrm{CC}$, and their specific actions to contribute to reducing $\mathrm{CC}$ impact.

\section{MATERIAL AND METHODS}

The aduslts perception on climate change was analyzed on the basis of a questionnaire survey that includied questions on public concern, knowledge and perception of the causes and impact of climate change, as well as their individual actions towards CC mitigation. The short term survey was provided among the urban and rural population in AP Vojvodina.

\subsection{The survey}

The survey contained two groups of questions: generaland specific questions. General group covered questions on age, gender, education, questionswith attention to analyze conceptual approaches to the problem of climate change. Also, this group included questions regarding personal views on climate change, their religious commitment as well as nationality.

Specific group of questions included following groups of questions: 1) personal attitude to the issue of climate change; 2 ) questions that reveals personal actions towards climate change mitigation and 3) questions that indicate knowledge on this topic.

Personal perception of knowledge and awareness of the problem of climate change include three questions:

1. I think that I know about climate change issues very well

2. I think that my actions are environmentally friendly

3. I feel self-responsibility and need to contribute CC mitigation

In order to examine personal acts and environmental activism, we questioned about type of energy source that participants use for household heating, and which type of energy source they would use if there are possibility to change it.

Real knowledge was investigated trought the direct and specific and questions: 
1. What is the couse of climate changes

2. What are the reneweble energy sources?

Also, the knowledge examined inderectly trought thepersonal action questions.

Some of the questions are formulated as a dummy variable (for gender) or an interval level variable (for age). Some question included a statement, with which participants could agree, disagree, or neither on a 5-point scale (i.e. Strongly Agree, Agree, Neither Agree nor Disagree, Disagree, Strongly Disagree), and some of the questions implied the option for participants to formulate their answer.

The questions that included free/opinion answers were revised and systematized into groups that included the most frequently represented answers.

\subsection{The participants}

This research was provided among adults in different regions of the province of Vojvodina (South Backa county, North Banat and Middle Banat County). The participants were moslyaged from 20-80 years old living in urban (227) and rural areas (70).

\section{RESULTS AND DISCUSSION}

The study included 297 participants, 224 female and 73 males. Age range is between $20-80$ years, whereas $74 \%$ are in range between $31-25$ years, $21 \%$ are aged $46-60$, while only $5 \%$ are in the age group below 31, and only two respondents (less than $1 \%$ ) are $60+$ age.

In terms of educational profile, the highest number of participants has technical background (18\%) and economic background (15\%), regardless of educational level. The highest percentage of high school educated participants (college, bachelor's degree, master degree) are within technical sciences (11\%) and pedagogy (9\%). Participants which holds PhDs, are from medical (2\%) and pedagogical sciences (2\%). $24 \%$ of respondents did not provide their educational profile. However, of these, $11 \%$ of respondents said they had completed only primary education, therefore is expected that they did not provide their educational profile.

After answering some introductory questions, respondents indicated whether they thought $\mathrm{CC}$ has been happening, and then answered questions about their opinions on related issue.

Over $60 \%$ examinees stated that their knowledge in CC issues was good, that their actions are environmentally friendly and that they feel personal responsibility and need for CC mitigation contribution. However, $18-28 \%$ of examinees, depending on statement, stated that they are totally agree. Also, less than $5 \%$ of examinees stated that they do not agree and more than $10 \%$ stated that they do have no opinion on these three statements (Fig.1).

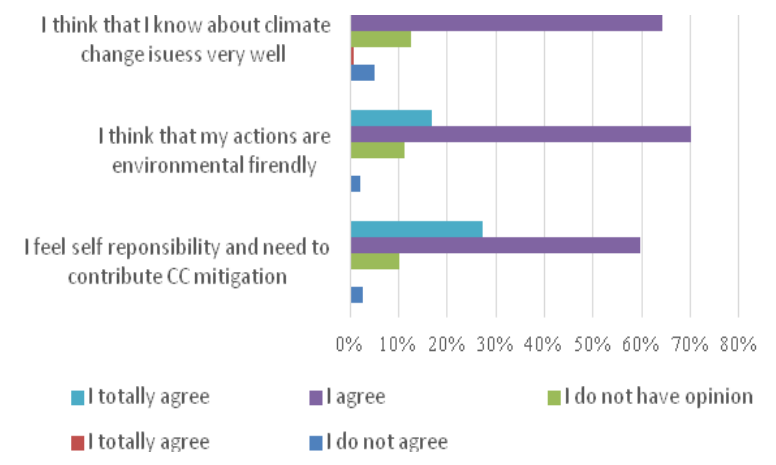

Fig.1. Personal perception of knowledge, responsibility and contribution to environmental protection

All the participants answered question: „Do you think that energy saving is very important for CC prevention? " and $85 \%$ agreed with this statement (Fig.2).

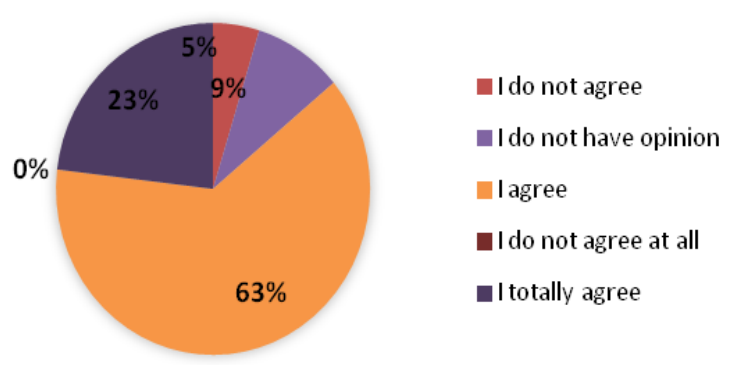

Fig.2. Importance of electricity saving as contribution to mitigate $\mathrm{CC}$

The question where participants should make a list of renewable energy (RE) sources, the answers are systematized and grouped into 4 groups. The group of correct answers included those who had at least one RE sources. Thus, even $64 \%$ of the respondents did not answer (NA) the question, a small percentage answered incorrectly or stated that they did not know the answer to the question, and only $24 \%$ wrote correct answer (Fig.3). 


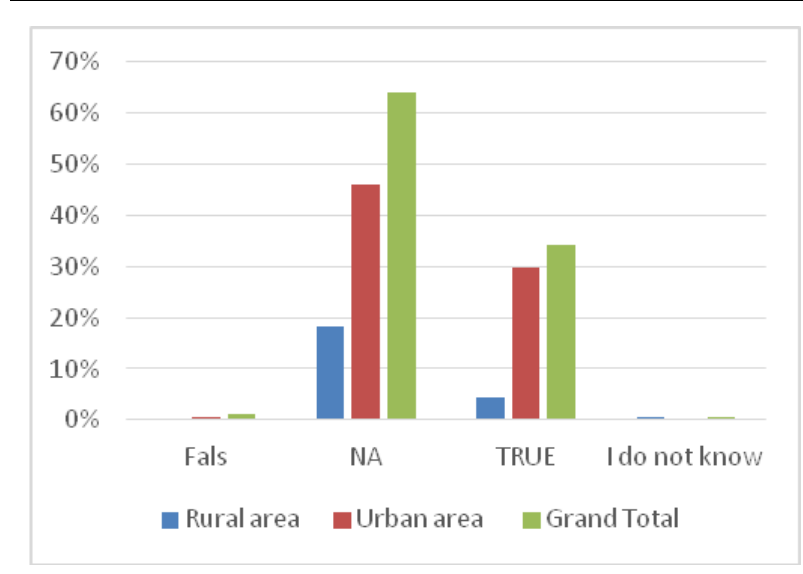

Fig.3. Name the renewable energy sources

The type of energy sources that participants use for household heating is presented at Fig.4. All the examinees answered this question. Typically, for urban areas, the dominant type of heating is natural gas (55\%) which is the main fuel in system of city heating. In rural areas wood is the most used for household heating.

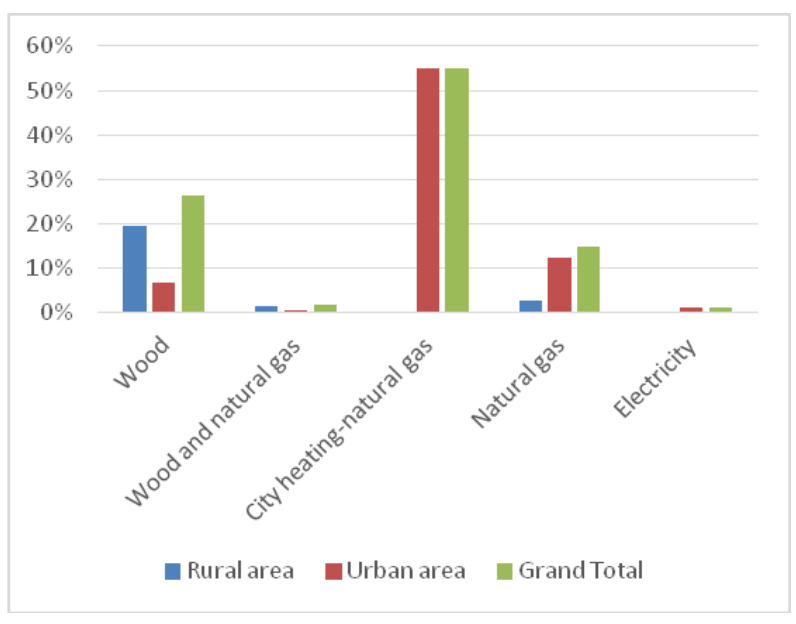

Fig.4. Share of energy sources used for household heating

Nevertheless, of the residence area, we learned that RE sources are not present for household heating, not even the RE sources that are available in this area (biomass or biogas).

On question: "If you have possibility to choose (change), which energy source you would pick for household heating?", $25 \%$ of examinees didn't answer (NA). Nearly the same percent (26\%), and the highest one, explicitly answered that their choice would be solar energy (SE). Furthermore, $17 \%$ of examinees choose natural gas and $8 \%$ answered that their choice would be any of RE sources (Fig.5).

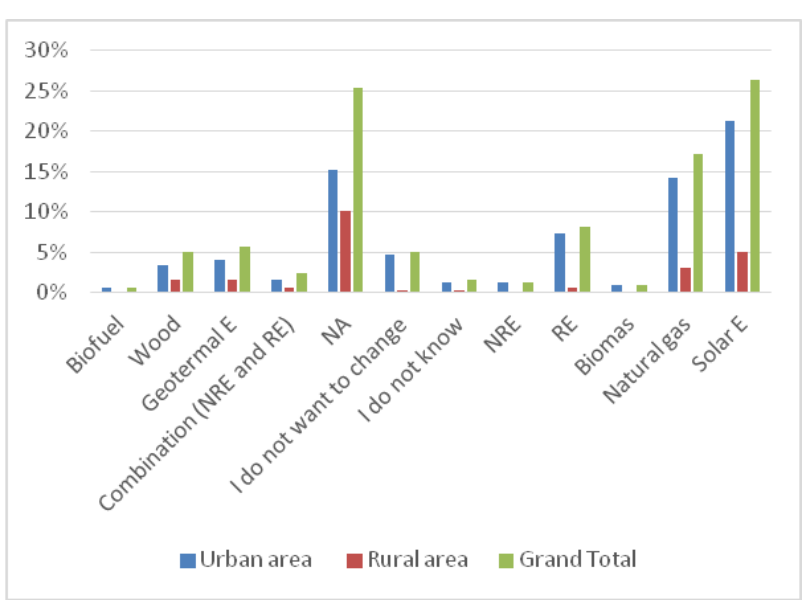

Fig.5. Choice/Selection of potential energy source

When asked why they would decide not to (change) energy source, as in previous questions, a significant proportion of respondents did not answer (NA) this question ( $25 \%$ in total).

Participants stated that solar energy would be their choice because it is environmentally friendly and financially acceptable.

Totally, $8 \%$ of participants stated that their choice would be any of RE sources because its environmentally friendly.

Participants who stated that they would not change energy type/source they used, are the one who use the city/public heating system for household heating, and they stated that it is the most economical heating option, and in addition they stated that they had no other choice/possibility for energy so they will not change the energy source (Fig.6).

There are wrong perception among one part of participants that natural gas is environmentally friendly. These participants stated that they are not ready to change this type of fuel/energy source because of the conformity and habits especially those who are users of city heating system. Additionally, the area of research is the only part of Serbia that has some gas and oil fields, so gas is available and financially affordable, according to the most participants. 


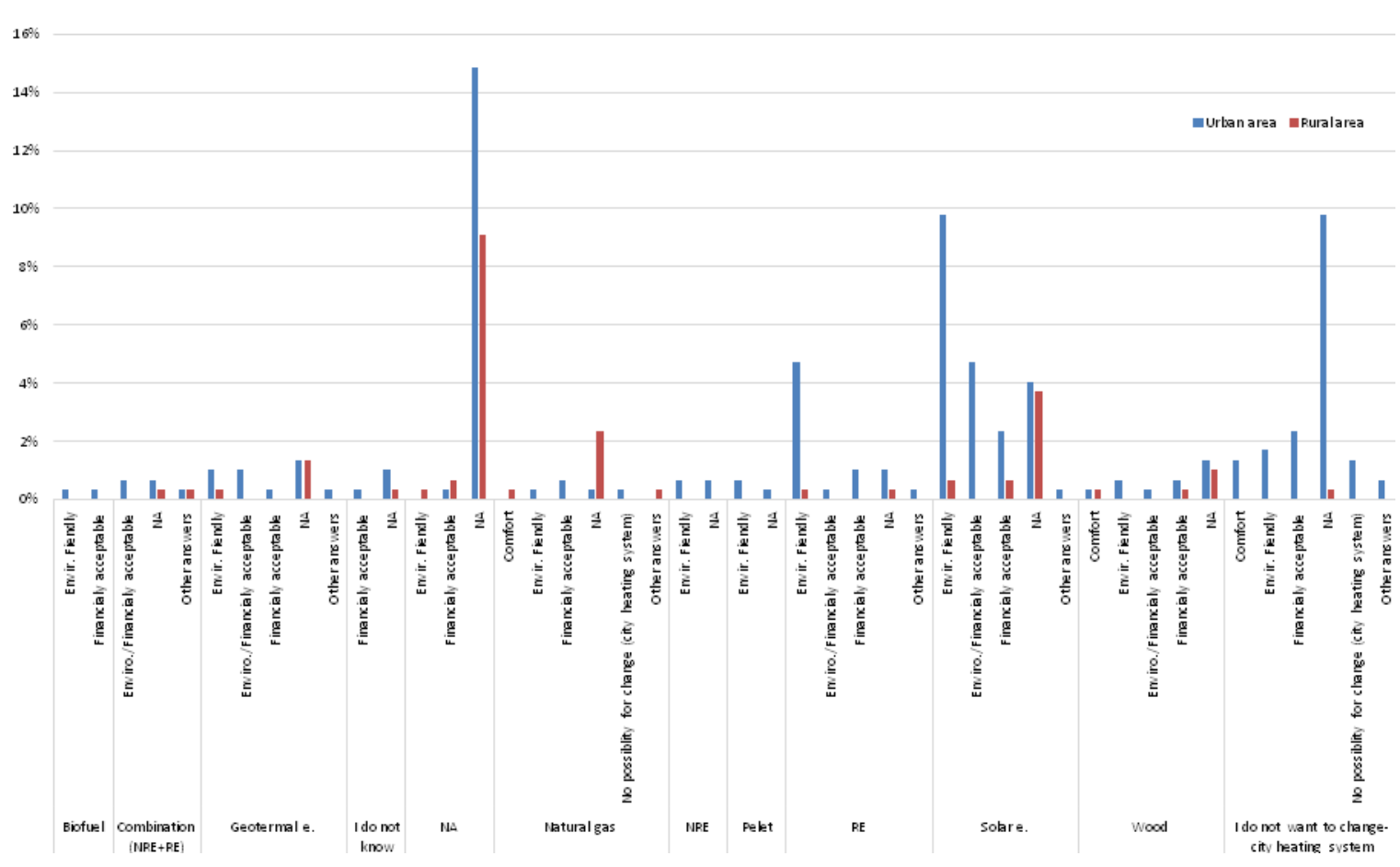

Fig.6. Participants' criteria for selection of RE sources

It is interesting, on question "How do you contribute to climate change mitigation" $51 \%$ of respondents did not answer (NA), while $16 \%$ said that the change of transport habits (hybrid cars, use of public transport, bicycles and walking), is one of possibilities to reduce the contribution to climate change. Also, $9 \%$ of respondents stated that the solution was rational use of energy and switching to RE sources. $6 \%$ of respondents cited improvement of waste management system (recycling, reduced use of plastic bags and plastic products) as a solution for climate change mitigation, and $7 \%$ cited general answers that included the need for education, responsible behavior and personal actions (Fig.7).

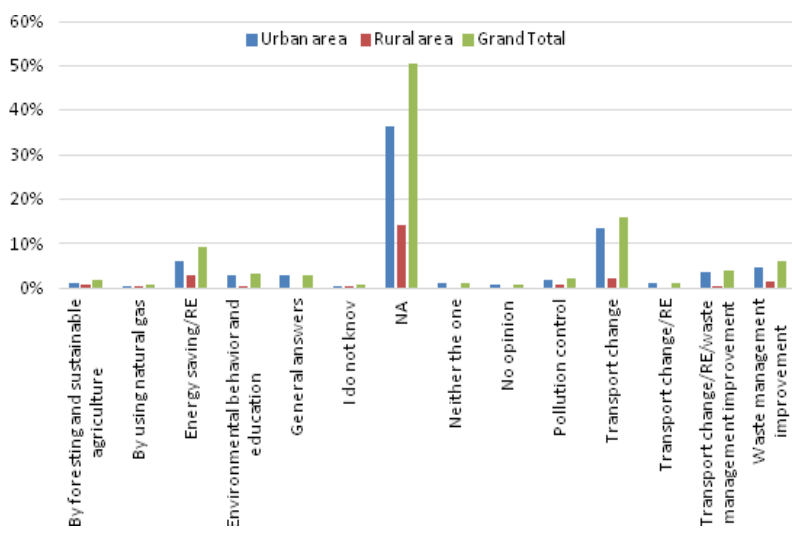

Fig.7. Participants actions that will contribute to reduce/mitigate the climate change impact
The proof that one part of participants think that natural gas does not pollute environment was found in answers that relate to the personal environmental action. So, some of the participants stated that using this energy source would be their contribution to the climate change mitigation.

Group of questions that reveals real knowledge indicated that adults are not completely sure what there the main cause of $C C$ and what are the renewable energy sources because the majority of the participants did not answer those questions.

\section{CONCLUSION}

This paper represents the results of the research on perception and knowledge of climate change issues, as well as a personal acts among 297 adults in urban and rural areas in province of Vojvodina.

Most of the examinees (52\%) that took our survey had higher education (college, faculty, master or PhD degree), mostly of the technical $(18 \%)$ and economics (15\%) profile.

Almost all the examinees answered on general questions, as well as on specific questions that refers on their personal CC perception and selfevaluation on their CC knowledge. However, in questions that reveals personal actions towards CC mitigation and questions that indicate knowledge on this topic, percent of "Not Answered "(NA) has risen from $15-45 \%$ depending on type of question. 
"NA" could be interpreted as lack of knowledge in particular topic. On other side, rest of the examinees that answered questions, especially the questions that indicate real knowledge and right actions toward the personal contribution to $\mathrm{CC}$ mitigation, has revealed high level of knowledge.

Finally, we can conclude that the awareness of CC and the knowledge on CC issue, among the adult population in rural and urban parts of Vojvodina are relatively polarized. Although the respondents expressed a high level of knowledge through self-evaluation and, consciously, the results show the opposite. Namely, a significant percentage of respondents did not answer the key questions that would indicate knowledge of CC problems, which is a key factor in the problemsolving approach itself.

Based on data obtained within this research, we could generally conclude that awareness among adults in urban parts of Vojvodina is high, but understanding and knowledge is at very low level.

\section{REFERENCES}

[1] T.R. Karl, J.M. Melillo, T.C. Peterson, Global Climate Change Impacts in the United States, (eds.). Cambridge University Press, 2009.

[2] K. Xu, X. Wang, C. Jiang, O.J. Sun, Assessing the vulnerability of ecosystems to climate change based on climate exposure, vegetation stability and productivity. Forest Ecosystems, 7 (23), 2020.

https://doi.org/10.1186/s40663-020-00239-y

[3] M.C. Urban, Accelerating extinction risk from climate change. Science, 348 (6234), 2015: 571-573.

https://doi.org/10.1126/science.aaa4984

[4] World Health Organisation. Climate change and health, 2018. http://www.who.int/newsroom/factsheets/detail/climate-change-andhealth (Accessed 15.03.2020).

[5] T. Crncevic, V. Orlović Lovren, Displacement and climate change: improving planning policy and increasing community resilience. International Journal of Climate Change Strategies and Management, 10 (1), 2018:105-120.

https://doi.org/10.1108/IJCCSM-05-2017-0103

[6] A. Ašonja, E. Desnica, Lj. Radovanović, Energy Efficiency Analysis of Corn Cob Used as a Fuel, Energy Sources, Part B: Economics, Planning and Policy, 12 (1), 2017: 1-7. http://dx.doi.org/10.1080/15567249.2014.88 $\underline{1931}$

[7] United Nations Development Programme, Promoting Sustainable Development Through More Effective Civil Society Participation in Environmental Governance: A Selection of Country Case Studies from the EU-NGOs Project. UNDP, New York, 2016.

[8] R.E. O'Connor, R.J. Bord, A. Fisher, Risk Perceptions, General Environmental Beliefs, and Willingness to Address Climate Change. Risk Analysis, 19 (3), 1999: 461-471.

https://doi.org/10.1023/A:1007004813446

[9] A.M. McCright, The effects of gender on climate change knowledge and concern in the American public. Population and Environment, 32 (1), 2010: 66-87.

https://doi.org/10.1007/s11111-010-0113-1

[10] A.T. Abelesa, L.C. Howeb, J.A. Krosnickc, B. Maclnnisa, Perception of public opinion on global warming and the role of opinion. Deviance Journal of Environmental Psychology, 63, 2019: 118-129.

https://doi.org/10.1016/i.jenvp.2019.04.001

[11] R.J. Bord, R.E. O'Connor, A. Fisher, In what sense does the public need to understand global climate change? Public Understanding of Science, 9 (3), 2000: 205-218.

https://doi.org/10.1088/0963-6625/9/3/301

[12] S. Capstick, L. Whitmarsh, W. Poortinga, N. Pidgeon, P. Upham, International trends in public perceptions of climate change over the past quarter century, Wiley Interdisciplinary Reviews: Climate Change, 6, 2015: 35-61.

https://doi.org/10.1002/wcc.343

[13] The Nielsen Company, 2009.

http://blog.nielsen.com/nielsenwire/wpcontent/uploads/2009/12/globalclimatechange-survey (Accessed 10.03.2020).

[14] Eurobarometer, Europeans' Attitudes Towards Climate Change, Special Eurobarometer 322, European Commission, 2009.

http://ec.europa.eu/public opinion/archives/ ebs/ebs 322 en.pdf (Accessed 7.02.2020).

[15] B. Ratter, K. Philipp, H. Von Storch, Between hype and decline: recent trends in public perception of climate change. Environmental Science \& Policy, 18, 2012: 3-8.

https://doi.org/10.1016/j.envsci.2011.12.007

[16] T. Lee, E. Markowitz, P. Howe, C.Y. Ko, A. Leiserowitz, Predictors of public climate 
change awareness and risk perception around the world. Nature Climate Change, 5, 2015: 1014-1020.

https://doi.org/10.1038/nclimate2728

[17] H. Yu, B. Wang, Y.J. Zhang, S. Wang, Y.M. Wei, Public perception of climate change in China: results from the questionnaire survey. Natural Hazards, 69, 2013:459-472.

https://doi.org/10.1007/s11069-013-0711-1

[18] C.P. Borick, B.G. Rabe, A Reason to Believe: Examining the Factors that Determine Individual Views on Global Warming. Social Science Quarterly, 91 (3), 2010: 777-800.

https://doi.org/10.1111/j.1540-6237.2010.00719.x

[19] A. Norton, J. Leaman, The Day After Tomorrow: Public Opinion on Climate Change. MORI Social Research Institute, 2004.
[20] O. Anisimov, R. Orttung, Climate change in Northern Russia through the prism of public perception. Ambio, 48, 2019: 661-671.

https://doi.org/10.1007/s13280-018-1096-x

[21] C.P. Borick, E. Lachapelle, B.G. Rabe, Climate Compared: Public Opinion on Climate Change in the United States and Canada. Issues in Governance Studies, 39, 2011.

[22] A. Sullivan, D.D. White, An Assessment of Public Perceptions of Climate Change Risk in Three Western U.S. Cities. Wea. Climate Soc. 11 (2), 2019: 449-463.

https://doi.org/10.1175/WCAS-D-180068.1 